\title{
Malpositioning of Central Venous Catheter: A Case Report
}

\author{
Vaishali Waindeskar ${ }^{1 *}$, Sheetal Songir ${ }^{2}$ and Rajeev $^{3}$ \\ ${ }^{1}$ Department of Anaesthesia and Critical Care, AIIMS Bhopal, India \\ ${ }^{2}$ Assistant lecturer, AIIMS Bhopal, India \\ ${ }^{3}$ Senior Resident, AIIMS Bhopal, India
}

Submission: June 18, 2018; Published: June 21, 2018

*Corresponding author: Vaishali Waindeskar, Department of Anaesthesia and Critical Care, AIIMS Bhopal, Madhya Pradesh, India, Tel: 919575604490; Email: vaishaliwaind@gmail.com
Abstract subclavian vein.
Keywords: Central venous catheter; Malposition; Subclavian vein
Abbreviations: CVC: Central Venous Catheter; SVC: Superior Vena Cava; RA: Right Atrium

Central venous catheter insertion is a commonly performed procedure in ICU and anaesthesia practice. Malpositioning of the central venous catheter through the subclavian vein is a rare complication. This case report describes Malpositioning of the catheter in the contralateral

\section{Introduction}

Central Venous Catheter (CVC) malpositioning is a frequently observed complication, ranging in incidence from 3 to $15 \%$ [1]. CVC insertion is still a blind process. Although use of ultrasoundguided insertion has advantage in terms of improved accuracy of insertion site, assessing the location of the tip of the catheter is still a challenge during insertion. Transoesophageal echocardiography can detect the location of the tip of the catheter in relation to the Superior Vena Cava (SVC) and Right Atrium (RA), but its availability as a bedside tool is very limited [2]. Most commonly a chest radiography is performed after the procedure to confirm the tip [3]. We report here a case of mispositioning of the catheter into the contralateral subclavian vein.

\section{Case report}

A 40-year-old female patient with a diagnosis of acute intestinal obstruction was admitted to the ICU for postoperative care. The patient became drowsy and developed fever on second postop day. It was decided to insert a central venous line for fluid management. A CVC was placed into the right subclavian vein by infraclavicular approach using Sledinger technique. The catheter was threaded over a guide wire and fixed at the recommended depth of $15 \mathrm{~cm}$. All three lumens were flushed, and intravenous fluid was started. Post procedural radiography confirmed insertion of the catheter tip into the contralateral subclavian vein (Figure 1). We decided to correct the tip position by pulling the catheter over the guide wire. The catheter was reinserted, and a radiograph was taken subsequently confirmed the tip position into the SVC above the RA.

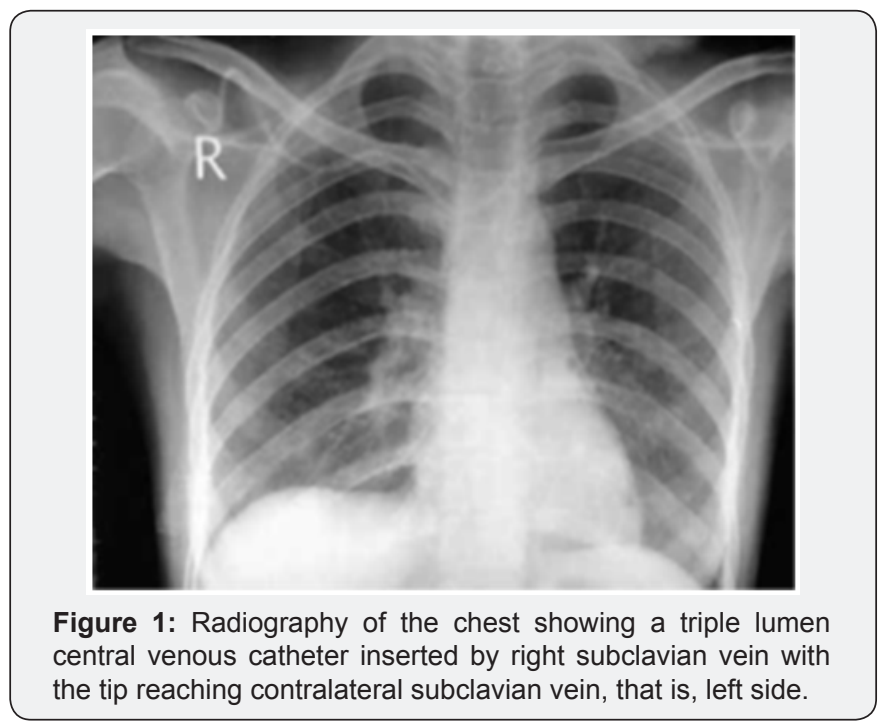

\section{Discussion}

Subclavian vein catheterization is a very commonly performed procedure in the ICU and anaesthesia practice. In normal course, the guide wire passes through the right subclavian vein, proceeds along the inside of the right brachiocephalic, and then toward the RA. The path taken by the guide wire is also dependent on the 
orientation of its tip [4,5]. During subclavian vein catheterization, the most common misplacement of the catheter happens in the ipsilateral internal jugular vein. Incidence of up to $60 \%$ is noted in some series [6]. Other mentioned sites are the thymic vein, the left superior intercostal vein, and the azygous vein. Complications associated with guidewire and catheter insertion are due to mechanical erosions arrythmia due to cardiac wall stimulation. Over insertion of the catheter into the heart chambers can be avoided by inserting the catheter at $16-17 \mathrm{~cm}$ [7].

Avoiding a bevelled or hard-tipped catheterand immobilization of the catheter have been recommended [8]. Placement of the tip in the extracardiac position in the SVC and confirming it by radiography is the most effective method. For catheter tip location three different zones have been mentioned with respect to the SVC [9]. Zone A suitable area for placement of a right-sided catheter, represents the lower SVC and upper RA. The catheter lies parallel to the vessel wall in this zone. Zone B represents the area around the junction of the left and right innominate vein and upper SVC. It is the most suitable area for placement of a right-sided catheter Zone C represents the left innominate vein proximal to the SVC. This zone is suitable for short-term therapy and central venous pressure monitoring (Figure 2). Site of insertion and the patient's height and body built are important factors that influence the catheter length. [10]

\section{Financial Support and Sponsorship}

Nil.

\section{Conflicts of Interest}

There are no conflicts of interest.

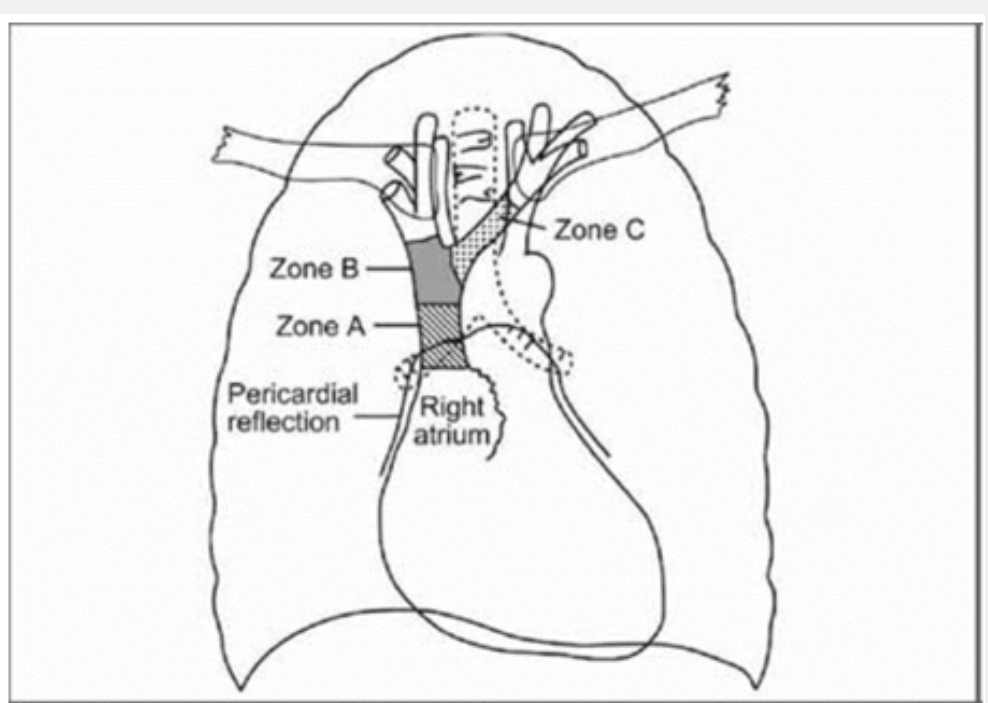

Figure 2: Schematic diagram of zone wise anatomy relevant to central venous catheter tip positioning [9].

\section{References}

1. Mc Gee DC, Gould MK (2003) Preventing complications of central venous catheterization. Engl J Med 348: 1123-1133.

2. Schummer W, Schummer C, Schelenz C, Schmidt P, Fröber R, et al. (2005) Modified ECG-guidance for optimal central venous catheter tip positioning. A transoesophageal echocardiography-controlled study. Anaesthesist 54(10): 983-990.

3. Kujur R, Manimala Rao S, Mrinal M (2009) How correct is the correct length for central venous catheter insertion? Indian J Critical Care Med 13(3): 159-162.

4. Park HP, Jeon Y, Hwang JW, Han SH, Bahk JH, et al. (2005) Influence of orientations of guidewire tip on the placement of subclavian venous catheters. Acta Anaesthesiol Scand 49(10): 1460-1463.

5. Tripathi M, Dubey PK, Ambesh SP (2005) Direction of the J-tip of the guidewire, in Seldinger technique, is a significant factor in misplacement of subclavian vein catheter: a randomized, controlled study. Anaesth Analg 100(1): 21-24.
6. Ambesh SP, Pandey JC, Dubey PK (2001) Internal jugular vein occlusion test for rapid diagnosis of misplaced subclavian vein catheter into the internal jugular vein. Anesthesiology 95(6): 1377-1379.

7. McGee WT, Ackerman BL, Rouben LR, Prasad VM, Bandi V, et al. (1993) Accurate placement of central venous catheters: a prospective, randomized, multicenter trial. Crit Care Med 21(8): 1118-1123.

8. Ezri T, Weisenberg M, Sessler DI, Berkenstadt H, Elias S, et al. (2007) Correct depth of insertion of right internal jugular central venous catheters based on external landmarks: avoiding the right atrium. J Cardiothorac Vasc Anesth 21(4): 497-501.

9. Stonelake PA, Bodenham AR (2006) The carina as a radiological landmark for central venous catheter tip position. Br J Anaesth 96(3): 335-340.

10. Czepizak CA, O Callaghan JM, Venus B (1995) Evaluation of formulas for optimal positioning of central venous catheters. Chest 107(6): $1662-1664$ 
This work is licensed under Creative Commons Attribution 4.0 License

DOI: 10.19080/JAICM.2018.07.555703
Your next submission with Juniper Publishers will reach you the below assets

- Quality Editorial service

- Swift Peer Review

- Reprints availability

- E-prints Service

- Manuscript Podcast for convenient understanding

- Global attainment for your research

- Manuscript accessibility in different formats

( Pdf, E-pub, Full Text, Audio)

- Unceasing customer service

Track the below URL for one-step submission https://juniperpublishers.com/online-submission.php 